\title{
Non-Metastatic Synovial Sarcoma
}

National Cancer Institute

\section{Source}

National Cancer Institute. Non-Metastatic Synovial Sarcoma. NCI Thesaurus. Code C8826.

Synovial sarcoma that is confined to the site in which it initially manifested. 